\title{
Multi-Criteria Decision Analysis in policy making for climate mitigation and development
}

\begin{abstract}
Greenhouse gas (GHG) mitigation policy making has largely been conducted in isolation of development considerations. An emerging literature, bolstered by the "nationally determined" nature of the Paris Agreement, explores the identification and assessment of the co-impacts of mitigation actions. There is now a recognised need to consider mitigation an integral part of a multi-objective development challenge. However, the literature on how to practically and effectively apply this in policy making, particularly in developing economies, is limited. This paper explores the potential for using approaches that fall under the umbrella of multi-criteria decision analysis (MCDA) in guiding analyses and policy-making that relate to the climate mitigation-development interface. It categorizes three distinct types of decision problems in the broad area of climate and development policy-making, and presents lessons from three case studies, in India, Chile, and Peru and Colombia taken together, where aspects of MCDA approaches were explored. Based on these reviews, the paper concludes that MCDA approaches, despite certain limitations, can add substantive and procedural credibility to existing toolkits supporting climate and development decision-making. Key contributions of the approach are to structure the analyses, systematically include stakeholder deliberations, and provide tools to rigorously incorporate quantitative and qualitative co-impacts in multipleobjective based decisions.
\end{abstract}

\section{Keywords}

mitigation, development, multi-criteria decision analysis, co-impacts, co-benefits, climate change, multiple objectives, energy, mainstreaming, developing countries

\section{Introduction: Overview of the policy challenge}

Greenhouse gas (GHG) mitigation analysis and policy has to a large degree been divorced from development related agendas in the institutions and political economies of most developing (and developed) countries (Tyler, 2015). Departments and ministries of environment and foreign affairs of national governments have for the most part driven climate mitigation at the national level, with differing levels of engagement and coordination between them and other development-related departments and ministries. However, over the past few years, it became clearer that policymaking for climate mitigation cannot operate in isolation from decision-making in other related sectors - as is reinforced by the frameworks of the 2015 Paris Agreement on climate action and the Sustainable Development Goals.

It is now well recognised that there are almost always synergies and trade-offs within and across the economic, environmental and social dimensions of development, which have implications for design and implementation of mitigation actions and policies. An absence of co-impacts of mitigation interventions is probably the exception rather than the rule (ÜrgeVorsatz, Tirado Herrero, Dubash \& Lecocq, 2014; von Stechow et al., 2015).

These issues are particularly important to developing economies, which face rapid and transformative changes, resulting in immense potential to avoid lock-in to high carbon and low resilient development pathways (Seto et al., 2016; Creutzig et al., 2016). Where climate 
mitigation actions have been implemented in developing countries, this has often been a result of developmental drivers such as energy efficiency, provision of public transport or waste reduction, which would have taken place even in the absence of climate action (Boyd \& Coetzee, 2013; Tyler, 2015). In reality, climate mitigation has commonly not been a political priority in most developing countries.

These considerations explain the interest of mitigation practitioners in finding alternative entry points to help support the case for increasing uptake of mitigation actions. This requires inputs from individuals across different disciplines, to analyse the non-mitigation impacts of mitigation action. Coordination across sectors and jurisdictions is also necessary to understand the interdependencies and systemic relationships between development and climate change action.

There is already a fairly extensive academic literature relating to the analysis of the coimpacts of mitigation action, including in developing countries (IPCC, 2014, Winkler, Boyd, Torres Gunfaus \& Raubenheimer, 2015; Tyler \& du Toit, 2014). This work has largely been approached from the perspective of trying to bring additional arguments to bear in favour of mitigation policy, rather than understanding mitigation policy as being an integral part of a larger development context. In other words, in this literature climate and development are still framed as separate issues.

The most recent literature seeking to advance the thinking on integration of these two policy arenas advocates for framing the analysis as one of simultaneously considering "multiobjectives". Since IPCC AR5 framed the climate mitigation challenge as a multi-objectives problem in the context of sustainable development and equity, a number of novel representations thereof have been developed (see Urge-Vorsatz et al., 2014 and von Stechow et al., 2015 for a comprehensive review). The public policy literature is also advocating multi-objective discourses and applying efforts into mainstreaming of climate change in economic and sectoral planning. Some of the examples cited in Ürge-Vorsatz et al. (2014) include China's local implementation plans tied to energy efficiency; India's National Action Plan on Climate Change, which is embedded in development goals; Brazil's climate policy linked to forestry policy; examples from EU and US; and Colombia's Sectoral Action Plans. Still, the narrative remains mainly at a theoretical or conceptual level.

Different methods are emerging for quantifying individual co-impacts of individual mitigation actions and policies with varying levels of complexity. Pros and cons of such methods are discussed extensively in the literature (Scrieciu, Belton, Chalabi, Mechler \& Puig, 2014; UrgeVorsatz et al., 2014). However, development of a clear framework and related tools to support decision-making that goes beyond quantifying individual co-impacts and operationalizes the multiple objectives approach is less advanced. There is little guidance on how a policy-maker can, ex ante, assess the synergies and trade-offs across different mitigation and development policy objectives when deciding on a particular policy, and experiences with implementation are even scarcer (Khosla, Dukkipati, Dubash, Sreenivas \& Cohen, 2015). Further practical guidance is needed to effectively support decision-making.

In this context, the objective of this review paper is to help inform a framework to address multi-objective based problems, particularly those posed by climate and development linkages. The paper focuses on tools that fall under the broad umbrella of multi-criteria decision analysis (MCDA). MCDA is not a technique or collection of tools, but rather an approach to management of complex policy decision making problems, recognizing that a prime source of conflict is the existence of different goals between different role-players. MCDA is thus concerned with structuring interests of role players in terms of operationally 
meaningful criteria; providing means by which performance of alternative policy options can justifiably be evaluated in terms of such criteria; and aggregating group preferences across criteria.

The paper begins by presenting an overview of MCDA approaches. It then provides a proposal for grouping the different problem types that could be suited to exploration via MCDA approaches. Thereafter three different applied studies in which the authors were directly involved are analysed to highlight how elements of MCDA approaches were applied, and where they added value. Finally a set of conclusions is drawn.

In presenting this analysis it is not the intention to propose MCDA as an exclusive framework to address the challenge, nor one without its limitations. Rather, the paper serves to provide practitioners with insights into an alternative or complementary set of methodologies to add to their existing toolkits. That is, the scope of this paper is to introduce the reader to the potential and advantages of deploying a MCDA framework for aiding decision-making in the areas of climate change mitigation and development, supplementing the narrative delivered by other more frequently deployed tools.

\section{Overview of MCDA}

Prior to exploring how MCDA might be applied in the context described in the previous section, a brief overview of the approaches common to MCDA analyses is presented. The starting point of a typical MCDA is a problem structuring exercise (see Marttunen et al. (2017) for an extensive literature review on problem structuring for MCDA, as well as Belton \& Stewart, 2002 and Belton \& Stewart, 2010). One of the most important components of problem structuring is that of defining the decision question or problem that is being addressed. While initially this may be considered to be self-evident, on reflection the problem question is frequently not as clear as initially thought. Different stakeholders might have a different understanding of the same problem or challenge. An alternative framing of the question may be more useful to the problem at hand or identify that the problem should be split into two or more separate problems. As such, spending time on defining what the purpose of the exercise is before launching into the process itself is central to increasing the likelihood of formulating politically-acceptable and effective solutions to the problem(s) identified.

Problem structuring can be tackled from an "alternative-focussed" perspective (basing selection of criteria on what is seen to differentiate alternatives most clearly), or a "valuefocussed" perspective (deriving criteria from an analysis of fundamental/deep goals/objectives of decision makers). Keeney (1992) pointed out that alternative-focussed thinking can lead to a lack of creativity in recognizing deficiencies in the alternatives on the table, which is why he introduced the value-focussed alternative. On the other hand, a full implementation of value focussed problem structuring can be overly time and resource consuming, much of it spent exploring irrelevant options. It is important, therefore, to draw on both alternative and value focussed thinking as appropriate (Belton and Stewart, 2010).

Stakeholder engagement is typically front-loaded during the project structuring phase, at the stage of defining the decision question. It is important that all relevant stakeholders are systematically identified, mapped and engaged with before the policy questions are defined and the analytical process begins. In high-level climate policy processes, that are the focus of this paper, it is critical that key decision makers are included in the process. This would typically require representation at the ministerial (and intergovernmental where applicable) level. It is also noted that different stakeholders offer different inputs into the process, with some individuals contributing to legitimacy of the process, others acting in an advisory 
capacity and still others acting as "experts", offering quantitative or scientific inputs to the analytical process. This would also suggest that different stakeholders might be involved at different stages - although to ensure ongoing buy-in it is important that key stakeholders be kept abreast of developments in the project throughout the process. Different modes of engagement may be employed, ranging from individual consultations, to small group meetings, to larger information workshops, to electronic communications and internet platform-based interactions. The involvement of stakeholders throughout ensures greater buy-in to the outcomes, provision of data and guidance to ensure that the process is on track. Furthermore, problems can be explored from the perspective of different stakeholders with different values and viewpoints.

Problem structuring also includes the identification of assessment criteria that in the climate mitigation and development context may include the economic costs of implementation, GHG emission reductions, employment creation and poverty alleviation amongst others. Clear, systematic processes are described in the literature for the identification of criteria, construction of an appropriate value tree or hierarchy of criteria through the synthesis of inputs from different stakeholders and experts (UNEP, 2011; Scrieciu et al., 2014). The value tree, for which a simplified example is illustrated in Figure 1, becomes the central framework for evaluation and assessment at various stages of the overall process.

Figure 1: Example of a value tree for a climate mitigation co-benefits MCDA process ${ }^{1}$ (UNEP, 2011, Scrieciu et al., 2014)

The rigorous approach to problem structuring helps to provide greater clarity on the decision problem that is being addressed. This is particularly useful in complex problems such as climate change mitigation coupled with meeting development agendas, which are considered messy problems (Ackoff, 1979) or sometimes wicked or super-wicked problems (Levin, Cashore, Bernstein \& Auld, 2012; Lazarus, 2009). Effective problem structuring helps to identify gaps and problems early on in the analysis, and to ensure that the information that is collected during the decision process is accurate and useful.

Once agreement has been reached on the problem structuring, the problem analysis stage begins with the evaluation of the performance of the alternatives in terms of each criterion. Finally, aggregation (which includes a weighting process) and ranking of alternatives may be undertaken to reach overall conclusions or recommendations. It is noted that the process is not necessarily linear, with multiple iterations between problem structuring and problem analysis being possible.

An important benefit of using MCDA approaches is that it allows for integrating nonquantifiable or qualitative criteria into a decision problem at the same level of analysis as quantitative criteria. Qualitative criteria may be assessed on constructed categorical scales. Both the appropriate scaling of quantitative measures and the definition of qualitative scales requires care, but the MCDA literature provides substantial guidance on these issues (Belton \& Stewart, 2002). Other approaches that do not include provisions to support the inclusion of qualitative criteria may lead to their being excluded from decision problems. However, the key question of which type of MCDA technique is most appropriate for which type of climate mitigation policy problem remains open and more research is needed along these lines (Taha \& Daim, 2013)

Before moving to more practical detail and case studies regarding the use of MCDA in policy making for climate mitigation and development, there is value in identifying some of the potential limitations of MCDA. The need for careful problem structuring and the concern that an over-emphasis on purely alternative focused thinking can stifle creativity was highlighted 
above. In addition, lack of care in problem structuring can lead to omission of important criteria, and/or to inclusion of sets of criteria that are not preferentially independent (see, for example, Belton and Stewart, 2002, for discussion), which can bias conclusions. Another more technical limitation is that the intuitive interpretation of MCDA model parameters may be at variance with the algebraic meaning, leading to misspecification. For example, many people have an intuitive sense of the concept of weights in MCDA, but the meaning of weights can differ dramatically between MCDA schools, so care is needed in eliciting weights consistent with the model being used.

With sufficient care, these limitations can be overcome, but this can be demanding in terms of time and effort, itself a limitation. On the other hand, it is suggested here that the critical nature of the policy matters under consideration here can justify significant investments of time and effort.

An extensive literature on MCDA is available to which the reader is referred for further information, including in areas that have some bearing on this current paper. Huang et al. (2011) provides an extensive literature review of applications of MCDA in the environmental sciences, while Munda (2005) presents a review on MCDA in sustainable development. Various review papers related to energy and energy planning are also found, including Abu Taha \& Daim (2013), Afgan \& Carvalho (2002), and Mardani et al. (2016). A smaller number of articles on MCDA in climate mitigation planning are found; these include Brown and Corbera (2003), Streimikiene \& Balezentis (2013) and Zhang, Worrell \& Crijns-Graus (2015).

\section{Types of problems suited to MCDA application}

Three distinct types of decision problems in the broad area of climate and development decision-making are argued to be well suited to the application of MCDA approaches. These are: (i) ranking and prioritisation of individual mitigation and development actions against multiple criteria, (ii) construction of portfolios of actions to form coherent strategic plans and (iii) assessment of performance of such action portfolios against different criteria. In climate change planning these three activities may often follow naturally from each other.

\section{Problem type 1: Ranking and prioritisation of individual mitigation and development actions}

The first type of decision problem relates to the identification and prescreening of individual mitigation and development actions against a set of development-related impacts with associated measurement criteria. Such actions may include different physical technologies that could be deployed (either independently or in combination with others), economic actions such as pricing or taxation policies, socio-political actions such as user education or policies on migration. These actions are not necessarily mutually exclusive or directly comparable "alternatives". They are elements that contribute to the construction of integrated strategic plans (discussed as the second and third problem types below).

Depending on the sector and mitigation actions considered, the development-related impacts and associated criteria to be used in the classification and prioritisation of actions could include those related to health (measured as, say, disability adjusted life years or cost of illness avoided (Wilkinson et al., 2009; Preval, Chapman, Pierse, Howden-Chapman \& The Housing, 2010)), employment opportunities (measured through indicators such as increased employment opportunities and distance to public transport (Porter, Lee, Dennelein \& Dowel, 2015; Moreno \& Lopez, 2008; Tourkolias \& Mirasgedis, 2011)), biodiversity impacts (number of species and hectares of forest restored (Phelps, Webb \& Adams, 2012; Strassburg et al., 
2012)) or water quality (water quality and soil composition (Wilcock, Quinn, Hudson \& Parkyn, 2008; Hamilton \& Akbar, 2010)).

There may or may not be a need here to aggregate performance of individual mitigation actions across performance criteria. As indicated previously, extensive guidance in weighting and aggregation is provided in the MCDA literature.

Such evaluations can help to focus further data gathering or research, and in constructing policy portfolios or frameworks that address particular development agendas. In conducting these kinds of assessments, however, it needs to be recognised that mitigation actions may not be directly comparable, and certainly not mutually exclusive, so that any attempt to absolutely rank actions is probably not meaningful.

\section{Problem type 2: Constructing portfolios of actions as part of a larger strategic plan}

The second type of problem potentially suited to application of MCDA is that of assembling individual actions into integrated portfolios of actions and policies, taking into consideration interactions between the individual elements and timing of implementation, in such a way as to yield the most desirable outcomes across a number of criteria. In other words, the extent to which actions may be synergistic or sub-additive is evaluated, towards construction of portfolios where the performance achieved by implementing the portfolio is greater than the sum of the performances of its individual action components (as assessed in the first problem type presented above). Other considerations to take into account when constructing portfolios are whether there is policy overlap and whether the timing and sequencing of the different policy actions in addition to their combination would matter in terms of projected performance outcomes. The existence of financial or other resource constraints also needs to be taken into account.

The number of potential combinations of actions to form the portfolios will typically be huge, and not amenable to explicit enumeration. Here the use of multi-objective mathematical programming techniques can help to identify optimal combinations. Put differently, MCDA methods could be used to identify efficient frontiers that represent optimal portfolio allocations of climate change actions and resources (see for example Convertino \& Valverde, Jr, 2013 for the case of ecosystem management under different climate change scenarios). There is significant value added in combining advances in MCDA approaches with progress in portfolio theory for better-informed climate mitigation policy analysis (Bazilian, Hibbs, Blyth, MacGill \& Howells, 2011). Typically a (relatively small) number or shortlist of different potentially optimal solutions will be generated by this portfolio selection stage, after which would follow a final stage for more detailed evaluation (the third problem type considered below). An illustration of this form of MCDA modelling and associated numerical computations in the contexts of a national research agenda (for wood products) in Finland is provided by Vilkkumaa et al (2013). More details on the more frequently used mathematical programming methods in the context of planning practice may be found in Miettinen et al (2008) (interactive computational methods) and Deb (2008) (evolutionary multiobjective optimization).

Some examples of the use of MCDA in this second project type in other sectors are identified in the literature. Miller \& Belton (2014) use MCDA to explore action portfolios, and potential synergies and negative interactions between two or more policy options, applying the analysis to the case of water resource management issues in the Sana'a Basin of Yemen. The authors highlight the importance of considering portfolios of actions rather than individual measures, emphasising the value of an interactive model capable of dealing with the complexity of policy interactions. 
The final problem type potentially suited to application of MCDA seeks to rank order the action portfolios described in the previous section and/or to select one to three alternatives for presentation to decision makers. This third problem type also has potential value in the international climate change negotiations, and could be valuable in the setting of country climate policy strategies and their Nationally Determined Contributions (NDCs).

The set of criteria used for evaluation here may need to be extended beyond those in the first and second problem type by further problem structuring processes to include criteria that are more broadly relevant to the system being modelled, which may include those of wider impacts beyond the direct impacts, and implementability and political acceptability considerations, which will depend on the specific problem context. This may require qualitative assessment by stakeholders or experts and/or the application of additional systems models.

The evaluation of policy alternatives against the chosen criteria will often require processing through a multitude of energy-environment-economy models and related techniques in order to simulate likely quantitative impacts, or through methods eliciting subjective judgement from stakeholders and/or experts in the case of qualitative assessments. Once again, value measurement or outranking models provide well-tested frameworks for evaluation against individual criteria, preference ranking and the aggregation across criteria to achieve the final recommendations.

This third problem type is also relevant for evaluation of scenarios are generated by means other than a formal portfolio construction as described as the second problem type. For instance, this may refer to the evaluation of future energy or low carbon world visions or of broad areas of action that decision-makers might wish to focus on within a specific sector or sub-sector. Examples include Browne, O'Regan \& Moles (2010) who deploy MCDA techniques to explore several alternative domestic heating and electricity policy scenarios in an Irish-city region (e.g. business-as-usual, demand-side management, renewable fuel substitution), or Diakoulaki \& Karangelis (2007) applying MCDA techniques (and comparing them to cost benefit analysis) to power generation scenarios in Greece.

\section{Lessons from three case studies}

There is little demonstrated evidence of where MCDA has been comprehensively used the strategic country level in the types of problems described in the previous sections. However, some of the authors of this paper have applied aspects of MCDA approaches in projects in Chile and India and in parallel processes in Peru and Colombia, as a way to shift decisionmaking process to explicitly consider linkages between the multiple sustainable development objectives, including those related to climate mitigation. Some of the experiences and learnings are presented here to demonstrate the types of insights that MCDA approaches might afford.

\subsection{MCDA-related process insights for improving climate policy making in Chile}

The Mitigation Action Plans and Scenarios (MAPS) Chile process set out to explore the potential for mitigating greenhouse gas emissions across the economy through 
implementation of a number of discrete mitigation interventions (MAPS Chile, 2016). It was recognised early on that the case for mitigation would need to be supported by an understanding of the co-impacts of the individual interventions, in line with the first problem type discussed previously. A multi stakeholder process, which forms part of the MCDA toolkit, was undertaken to provide this understanding. The learnings from the case study presented here demonstrate the potential value of multi-stakeholder engagements for such problem types.

Through the participation of a multi-stakeholder group of nearly 100 people from private, public and civil society sectors who played an advisory role to the project, and the project steering committee (public officials from seven Ministries (finance, foreign affairs, agriculture, transport, mining, energy, environment)), eleven mitigation measures were chosen to be the focus of the co-impacts analysis (Table 1). Over fifty experts on the co-impacts of the measures were invited to participate in the process of exploring the conditions that would maximize positive developmental impacts and minimize negative developmental impacts associated with these measures (MAPS Chile, 2016). The process included three half-day meetings over a period of three months. The first meeting focussed on agreeing on the general methodology to be used for the assessment, and required the experts to identify and agree on relevant co-impacts for each of the selected mitigation measures. In the second meeting, experts were asked to describe each of the co-impacts and to identify what would determine the extent and magnitude of each co-impact. In the final meeting the experts suggested possible indicators and sources of information for quantification, as well as relevant national and international experience on the co-impact and/or mitigation measure.

Some of the key highlights from this process are as follows. First, MCDA-like processes have the ability to catalyse conversations that would otherwise not occur. Second, the structuring of the problem, through developing hierarchies that make explicit the relationships between the different co-impacts, adds clarity to a very complicated analysis. Some of the mitigation measures considered have more than ten co-impacts associated with them (in the different developmental dimensions: environmental, economic, social and institutional), with intricate relationships between them.

Third, this MCDA-like approach facilitates interactions between a wide range of experts and stakeholders. For instance, in the case of the electricity generation measures (big scale hydro generation in Chile's Patagonia and clean carbon power stations), experts on indigenous communities had the opportunity to interact with hydraulic and electrical engineers and other social and natural science experts. Such interactions on decisions with multiple impacts have not in general been common practice, at least not in Chile. These discussions, although challenging to manage, tend to be much richer than those that typically occur between those working in the same or related disciplines.

It is interesting to note that INDC deliberations, which were later led by Chilean government representatives, considered much of the evidence generated by MAPS Chile. Nonetheless, it is still early to assess the extent to which the results will guide actual policy decision-making and implementation.

\subsection{Policy Insights from using MCDA for sectoral analysis in India}

In India, two case studies were conducted which sought to initiate a structured conversation in policy making circles about ways to work through the complexity of development planning while accounting for climate considerations. MCDA was put forward by researchers as a 
potentially useful framework to facilitate such discussions, instead of being positioned as a rigid decision tool (Khosla et al., 2015). The process served to demonstrate to policymakers and experts how MCDA can highlight synergies and trade-offs across different policy objectives within a sector, making it fit squarely into the second problem type described in Section 3.

The first case study explored the ranking of policies for modern cooking fuels in rural households, while the second sought to evaluate energy efficiency policies for new residential building envelopes. Working through the case studies revealed that MCDA's key potential lies in its ability to explicitly structure policy decision-making, requiring decision makers to ask policy relevant questions and identify complementarities and trade-offs between the multiple objectives that the country faces. This is because the approach requires an explicit statement of all policy objectives, and the relative weight given to each. For example, the economic, social, environmental and institutional objectives of the cooking sector were explicitly laid out ex-ante. This encouraged consideration of often ignored factors, such as household drudgery, which are difficult to measure yet important to household decisions regarding which fuel to use, and ultimately in policy implementation. The approach also required identifying the relative weights across the set of identified objectives, such as minimizing household air pollution versus reducing greenhouse gas emissions. This attention enhanced the transparency and effectiveness of the final result.

While the outcomes of this exercise were preliminary, its sectoral application demonstrated that qualitative analysis, which the MCDA approach incorporates, but which are otherwise often left out of other more conventional analyses in India, are crucial to consider. For example, through the inclusion of implementation obstacles that are qualitative in nature (e.g., lobbies by interest groups, capacity availability and constraints), the results of the analysis shifted considerably. This was clear in the buildings case, where the building energy code policy fared best on environmental, social and economic fronts, but worst on ease of implementation, making the operationalization dimension of the policy central to whether it should be a preferred choice or not.

Finally, the initial application of an MCDA approach once again brought forth the need for an early involvement of stakeholders. Ideally, these would include technical experts, policymakers, industry, end-users and civil society (the first set of case studies were not able to cover this full spectrum). For example, in the cooking case, it was made clear that it is important to understand the preferences of the groups targeted - in this case, cook stove users (usually women) to assess the relative importance of reducing household drudgery from acquiring fuel-wood for a traditional cookstove, versus the increased costs from modern cooking equipment and fuel. The case study revealed that this broadening of the information base to include relevant stakeholders likely adds to the complexity of the process, but certainly enhances buy-in and enriches the analytical base.

Overall, the process of deliberation and repeated iteration while working through the case studies improved the sectoral knowledge base. The buildings example is a case in point, as answering the policy problem required researching data varying from the upfront investment needed for efficient materials, to the local pollution reduced from lower diesel generator use.

Both sectoral exercises made clear that MCDA approaches offer a useful way to work within the complexity of Indian energy and climate decision making, and can be a starting point for more structured and inclusive policy making, including the development of policy portfolios. This intent was motivated by a recognized need for Indian policies to be embedded within a process of transparent discussion, especially about underlying assumptions, sensitivities, and 
reasoning that lead to a particular result. While it was acknowledged that MCDA approaches can be perceived as complicated and are not trivial to implement, it was also agreed that they can help to enable India's energy and climate actions to be more compatible with its broader social, economic and environmental goals.

\subsection{MCDA-related lessons from Peruvian \& Colombian long- term planning processes}

Peru $^{2}$ and Colombia ${ }^{3}$ each established processes to produce and evaluate a set of nationally relevant development scenarios that include different portfolios of mitigation options. Although the framing of the processes was initially centred on climate mitigation, early on there was a recognition that the development context and agenda also need to be taken into account in constructing the development scenarios, through consideration of co-benefits or co-impacts of the scenarios. The final outcomes are thus aligned with the third problem type described previously.

In the early stages of their process, Colombia also used aspects of MCDA to support evaluation of individual mitigation actions by assessing their impacts in a number of individual criteria (although they did not progress through to aggregation of scores). The Colombians thus made use of MCDA in the first problem type here. Peru also used results from assessment of co-benefits of mitigation actions in the packaging of policy options into various scenarios as per the second application type.

Both processes took place under the Mitigation Action Plans and Scenarios (MAPS) Programme ${ }^{4}$ between 2011-2015. As was the case in MAPS Chile, they combined extensive stakeholder engagement with deep quantitative research to provide credible emissions projections, climate mitigation potentials and indications of social and economic implications of mitigation. The processes were also each supported by a high-level government mandate. A selection of the key learnings is as follows.

The first of these, which aligns with the Chilean and Indian case studies, is the significant value in including stakeholders in the process from early on, all the way from problem structuring through to problem analysis and the interpretation of results. This is considered to be one of the strengths of both country processes, with practical implementation of the theoretical concept of co-production of knowledge. As a result of the approach taken, shifts in the perspectives of a wide range of stakeholders from positions of scepticism or resistance to deep involvement in the processes were observed. The outcome was a far wider buy-in to the outcomes than might have been achieved without these processes. The selection of stakeholders is thus critical to the success of the processes - who participates, when and in what capacity are key decisions to be revisited throughout the decision process.

Secondly, from trialling various analytical approaches across the two countries (some more successfully than others), it was observed that the level of complexity and commitment required of stakeholders in the analyses should not be too great as to alienate stakeholders. Stakeholder fatigue becomes a very real challenge in any decision or analysis process such as those undertaken as part of MAPS.

Thirdly, Peru and Colombia encountered various challenges with respect to data availability to populate performance of alternatives in different criteria. Although data was gathered from a wide range of sources, various assumptions still needed to be made. Where full quantitative data was not available, constructed scales as described previously were trialled in both Peru 
and Colombia. However after initial attempts the constructed scales were not taken further due to challenges with their development, and detailed methodologies for converting the coimpacts to financial measures were developed ${ }^{5,6}$. Energy-environment-economy models were also developed and used to depict the social and economic implications of alternative mitigation scenarios towards supporting problem type 3 . The models provided an understanding of the quantitative impacts, however there was limited application of structured frameworks for the systematic evaluation of a wider range of policy impacts and options, such as those being proposed in this paper.

Fourthly, the decision as to whether it is appropriate to aggregate different criteria, and how such aggregation should be undertaken, can represent a significant process challenge. As discussed previously in this paper, aggregation is linked to stakeholders' values, and unpacking and capturing these values can be a time consuming and controversial process. Furthermore, while aggregation offers the advantage of providing single indicators of performance, it does have the potential to obscure issues that decision-makers and the public would rather treat explicitly. Put differently, the MCDA approach can deliver a single number measuring the performance of a policy option or portfolio as in the case of more conventional least-cost optimisation modelling methods. However, it can also leave a stronger trail of evidence by circumventing the pitfalls of aggregation and allowing stakeholders to collectively reach decisions based on multiple indicators of policy performance.

Finally it is noted that neither Peru nor Colombia applied a single coherent MCDA-type approach to the analyses conducted. There was much trial and error to attempt to establish what worked and what did not. The work did, however, point to the need for more structured approaches to support analyses, as could be offered by MCDA (Cohen, Tyler \& Torres Gunfaus, 2016).

\section{Conclusions}

MCDA is widely used to analyse complex decision-making problems with multiple competing or complementary objectives. It is also a powerful approach for the engagement of stakeholders with divergent or convergent values and priorities. Climate mitigation policy and planning, being strongly embedded in development strategies and challenges, is typical of such problems, and hence may be suited to the application of MCDA. However, there are few practical examples of where this has actually occurred, particularly when applied at the macro, strategic policy level and when closely linked to economy-wide development agendas. The review presented here suggests that MCDA has the potential to respond to the need for integrated development and climate policy analysis.

Three main findings or benefits of advancing the use of MCDA at the climate-development interface are identified. First, and most importantly, the MCDA approach has the valuable potential of being able to systematically map interactions between different low-carbon and development related policies and measures. This is of high value to policy makers, as there are increasing calls across the globe for closer integration of climate and development agendas. Governments clearly wish to make best use of their resources and avoid overlapping or conflicting policies and the MCDA framework may help address these concerns.

A second benefit highlighted both in the literature and the three case studies put forward in this paper is that of structured stakeholder involvement. This supports the democratisation of decision-making and ensuring all important aspects of the analysis have been included and are transparently communicated. Furthermore, it is evident from the use of MCDA in India 
and the MCDA-like approach used in Chile, Peru and Colombia that the inclusion of a broad variety of stakeholders and experts not only encourages buy-in from all levels but also enriches the process and data generation and use.

Finally, the third benefit of pursuing the MCDA route is that it ensures a structured, rigorous, yet flexible approach to analysing the multiple synergies and trade-offs between various climate and development policy options and portfolios.

A MCDA framing thus enables analysts and practitioners to focus on socially acceptable strategies that could achieve politically agreed goals, rather than to identify the cost "optimal" level of a target. ${ }^{7}$ In other words, it can support decision-makers in determining climate mitigation strategies that are not only low-cost, but are also compatible with pro-poor, environmental and other socioeconomic imperatives. It is then up to the concerned stakeholders to decide which strategies to adopt based on the knowledge and evidence generated via MCDA's interdisciplinary analysis.

It is worthwhile emphasising that MCDA is not a method or collection of methods, but rather a framework for thinking. The effectiveness and value of this framework is dependent upon careful structuring of the problem, alternating between alternative focused and value focused thinking, and in particular on the selection of criteria. Implementation of specific MCDA models also requires care in matching elicitation of parameters (representing preferential values in the models) with their theoretical meaning in the model. Lack of attention to such detail in structuring and value elicitation can introduce biases into the results, so that time and effort is needed with the process. On the other hand, experience has shown that MCDA results are quite robust to input assumptions, which can be checked by sensitivity analysis.

It isrecognised that MCDA is as of yet unproven systematically in the area of climate change mitigation macro-planning and mainstreaming into development policy strategies. MCDA can also be time and resource intensive, which may deter decision makers not acquainted with the benefits that it has to offer. As such, opportunities should be sought for further trialling of these tools and approaches to determine whether or not their application can add significant value in this particular policy evaluation and decision-making area.

\section{Notes}

1. The criteria tree illustrated here is structured in three layers. The first level consists of input (investments and efforts required) and output (impacts) criteria against which climate policy options are evaluated. The second level comprises seven criteria groups, two on the input side and five on the output side, whereas the third level refers to nineteen criteria, four associated with inputs and fifteen linked to outputs.

2. http://planccperu.org/

3. http://www.minambiente.gov.co/index.php/ambientes-y-desarrollossostenibles/cambio-climatico

4. http://www.mapsprogramme.org

5. http://www.minambiente.gov.co/images/AsuntosMarinosCosterosyRecursosAcuatico/ Metodologia Cobeneficios.pdf, available in Spanish only

6. http://planccperu.org/wp-content/uploads/2017/02/Estudio-4.-Analisis-decobeneficios-de-las-opciones-de-mitigacion.pdf, available in Spanish only 
7. It is important to note that there is no unique definition of "costs" in the climate change mitigation impact assessment literature. Costs may be represented by different indicators depending on the type of modelling approach and level of analysis, amongst others, being pursued. For example, mitigation costs may be split into energy system costs (the costs for the transition of the energy system), the area under the marginal abatement cost (MAC) curve, changes in consumption, changes in welfare or changes in GDP (Edenhofer et al., 2010, Paltsev \& Capros 2013). The fact that multiple definitions are given to "mitigation costs" in the literature further argues for the advantages of the MCDA approach, from this perspective of explicitly dealing with the multifaceted aspects of costs, over more traditional methods, such as least-cost optimisation, which focus on a particular definition of cost in order to reach a single aggregated indicator of policy performance.

\section{References}

Abu Taha, R., Daim, T. (2013). Multi-Criteria Applications in Renewable Energy Analysis, a Literature Review, in: Daim, T., Oliver, T., Kim, J. (Eds.), Research and Technology Management in the Electricity Industry. Springer, London, pp. 17-30.

Ackoff, R.L. (1979). Resurrecting the future of operational research, Journal of the operational research society, 30(3), 189-199.

Afgan, N.H., \& Carvalho, M.G. (2002). Multi-criteria assessment of new and renewable energy power plants. Energy 27, 739-755.

Antunes, C.H. \& Henriques, C.O. (2014). Multi-objective optimisation and multi-criteria decision analysis in the energy sector (part II - MCDA), European Working Group "Multicriteria decision aiding, 3(29).

Bazilian, M., Hobbs, B. F., Blyth, W., MacGill, I., \& Howells, M. (2011). Interactions between energy security and climate change: A focus on developing countries. Energy Policy, 39(6), 3750-3756.

Belton, V., \& Stewart, T. (2002). Multiple criteria decision analysis: an integrated approach: Springer Science \& Business Media.

Belton, V. \& Stewart, T.J. (2010). Problem Structuring and MCDA. In M. Ehrgott, J. Figueira \& S. Greco (Eds.), Trends in Multiple Criteria Decision Analysis (pp. 209-239). Springer.

Boyd, A., \& Coetzee, K. (2013). Mitigation action implementation: Towards an understanding of the variables that affect implementation of mitigation actions. Retrieved from http://www.mapsprogramme.org/wp-content/uploads/Paper PIMP-I working-paper final.pdf

Brown, K., Corbera, E., 2003. A Multi-Criteria Assessment Framework for Carbon-Mitigation Projects: Putting "development"in the centre of decision-making, in: European Application in Ecological Economics Conference Proceedings, Tenerife. Citeseer.

Browne, D., O'Regan, B., \& Moles, R. (2010). Use of multi-criteria decision analysis to explore alternative domestic energy and electricity policy scenarios in an Irish city-region. Energy, 35(2), 518-528. 
Census of India (2011). Houselisting and Housing Census Data. Retrieved from http://www.censusindia.gov.in/2011census/hlo/HLO Tables.html

Cohen, B., Tyler, E. \& Torres Gunfaus, M. (2016). Lessons from co-impacts assessment under the Mitigation Action Plans and Scenarios (MAPS) Programme. Accepted for publication in Climate Policy, 2017.

Convertino, M., \& Valverde Jr, L. J. (2013). Portfolio decision analysis framework for valuefocused ecosystem management. PloS one, 8(6), e65056.

Creutzig, F., Fernandez, B., Haberl, H., Khosla, R., Mulugetta, Y., \& Seto, K. C. (2016). Beyond Technology: Demand-Side Solutions to Climate Change Mitigation. Annual Review of Environment and Resources, 41(1).

Deb K. (2008) Introduction to Evolutionary Multiobjective Optimization. In: Branke J., Deb K., Miettinen K., Słowiński R. (eds) Multiobjective Optimization. Lecture Notes in Computer Science, vol 5252. Springer, Berlin, Heidelberg.

Diakoulaki, D., \& Karangelis, F. (2007). Multi-criteria decision analysis and cost-benefit analysis of alternative scenarios for the power generation sector in Greece. Renewable and Sustainable Energy Reviews, 11(4), 716-727.

Dubash, N.K. \& Joseph, N. (2015). The Institutionalisation of Climate Policy in India: Designing a Development-Focused, Co-Benefits Based Approach. Centre for Policy Research. Retrieved from http://www.mapsprogramme.org/wp-content/uploads/Dubash-andJoseph The-Institutionalisation-of-Climate-Policy-in-India 2015.pdf

Edenhofer, O., Knopf, B., Barker, T., Baumstark, L., Bellevrat, E., Chateau, B., Criqui, P., Isaccs, M., Kitous, A., Kypreos, S. (2010). The economics of low stabilization: model comparison of mitigation strategies and costs. The Energy Journal, 11-48.

Hamilton, K. \& Akbar, S. (2010). Assessing the Environmental Co-Benefits of Climate Change Actions. Retrieved from http://siteresources.worldbank.org/ENVIRONMENT/Resources/2443801250028593656/6382907-1252510780845/6428643-1256655379723/65108061258739266750/6594179-1279218279812/20101115-Assessing-Co-benefits-of-ClimateChange-Nov-15.pdf

Huang, I.B., Keisler, J., Linkov, I. (2011). Multi-criteria decision analysis in environmental sciences: Ten years of applications and trends, Science of The Total Environment, 409(19), 3578-3594.

IPCC, (2014). Climate Change 2014: Mitigation of Climate Change. Contribution of Working Group III to the Fifth Assessment Report of the Intergovernmental Panel on Climate Change [Edenhofer, O., R. Pichs-Madruga, Y. Sokona, E. Farahani, S. Kadner, K. Seyboth, A. Adler, I. Baum, S. Brunner, P. Eickemeier, B. Kriemann, J. Savolainen, S. Schlömer, C. von Stechow, T. Zwickel and J.C. Minx (eds.)]. Cambridge University Press, Cambridge, United Kingdom and New York, NY, USA.

Khosla, R., Dukkipati, S., Dubash, N. K., Sreenivas, A., \& Cohen, B. (2015). Towards Methodologies for Multiple Objective-Based Energy and Climate Policy. Economic \& Political Weekly, 50(49), 49-59.

Kumar, S., R Kapoor, R Rawal, S Seth \& A Walia (2010). Developing an Energy Conservation Building Code Implementation Strategy in India, New Delhi: USAID India.

Lazarus, R.J. (2009). Super Wicked Problems and Climate Change. Retrieved from http://www.lawschool.cornell.edu/research/cornell-law-review/upload/Lazarus.pdf 
Levin, K., Cashore, B., Bernstein, S., \& Auld, G. (2012). Overcoming the tragedy of super wicked problems: constraining our future selves to ameliorate global climate change. Policy Sciences, 45(2), 123-152.

MAPS Chile (2016). Opciones de mitigación para enfrentar el cambio climático y lograr un desarrollo bajo en carbono; síntesis de resultados de Fase 3.Ministerio del Medio Ambiente y Gobierno de Chile, Santiago, Chile.

Mardani, A., Zavadskas, E.K., Khalifah, Z., Zakuan, N., Jusoh, A., Nor, K.M. \& Khoshnoudi, M. (2016). A review of multi-criteria decision-making applications to solve energy management problems: Two decades from 1995 to 2015. Renewable and Sustainable Energy Reviews, 71, May, 216-256.

Marttunen, M., Lienerta, J., \& Belton, V., Structuring problems for Multi-Criteria Decision Analysis in practice: A literature review of method combinations, European Journal of Operational Research 263 (2017), 1-17.

Moreno, B., \& Lopez, A. J. (2008). The effect of renewable energy on employment. The case of Asturias (Spain). Renewable and Sustainable Energy Reviews, 12(3), 732-751.

Miettinen K., Ruiz F. \& Wierzbicki A.P. (2008). Introduction to Multiobjective Optimization: Interactive Approaches. In: Branke J., Deb K., Miettinen K., Słowiński R. (eds) Multiobjective Optimization. Lecture Notes in Computer Science, vol 5252. Springer, Berlin, Heidelberg

Munda G. (2005) Multiple Criteria Decision Analysis and Sustainable Development. In: Multiple Criteria Decision Analysis: State of the Art Surveys. International Series in Operations Research \& Management Science, vol 78. Springer, New York, NY.

Miller, K. A., \& Belton, V. (2014). Water resource management and climate change adaptation: a holistic and multiple criteria perspective. Mitigation and adaptation strategies for global change, 19(3), 289-308.

Paltsev, S., \& Capros, P. (2013). Cost concepts for climate change mitigation. Climate Change Economics, 4(supp01), 1340003.

Phelps, J., Webb, E. L., \& Adams, W. M. (2012). Biodiversity co-benefits of policies to reduce forest-carbon emissions. Nature Climate Change, 2(7), 497-503.

Porter, C., Lee, J., Dennerlein, T. \& Dowell, P. (2015). Selected Indirect Benefits of State Investment in Public Transportation, National Cooperative Highway Research Programme. Retrieved from: http://onlinepubs.trb.org/onlinepubs/nchrp/nchrp rrd 393.pdf

Preval, N., Chapman, R., Pierse, N., Howden-Chapman, P., \& Housing, T. (2010). Evaluating energy, health and carbon co-benefits from improved domestic space heating: A randomised community trial. Energy Policy, 38(8), 3965-3972.

Read, L., Madani, K., Mokhtari, S., \& Hanks, C. (2017). Stakeholder-driven multi-attribute analysis for energy project selection under uncertainty, Energy, 119, 744-753.

Scrieciu, S. Ş., Belton, V., Chalabi, Z., Mechler, R., \& Puig, D. (2014). Advancing methodological thinking and practice for development-compatible climate policy planning. Mitigation and adaptation strategies for global change, 19(3), 261-288.

Seto, K. C., Davis, S. J., Mitchell, R. B., Stokes, E. C., Unruh, G., \& Ürge-Vorsatz, D. (2016). Carbon Lock-In: Types, Causes, and Policy Implications. Annual Review of Environment and Resources, 41(1), 425-452. doi:doi:10.1146/annurev-environ-110615-085934

Smith, K. R., Bruce, N., Balakrishnan, K., Adair-Rohani, H., Balmes, J., Chafe, Z., Dherani, M., Hosgood, H.D., Mehta, S., Pope, D. \& Rehfuess, E. (2014). Millions dead: how do we know and what does it mean? Methods used in the comparative risk assessment of household air pollution. Annual review of public health, 35, 185-206. 
Somanathan E., T. Sterner, T. Sugiyama, D. Chimanikire, N.K. Dubash, J. Essandoh-Yeddu, S. Fifita, L. Goulder, A. Jaffe, X. Labandeira, S. Managi, C. Mitchell, J.P. Montero, F. Teng, \& T. Zylicz, 2014. National and Sub-national Policies and Institutions. In: Climate Change 2014: Mitigation of Climate Change. Contribution of Working Group III to the Fifth Assessment Report of the Intergovernmental Panel on Climate Change [Edenhofer, O., R. Pichs-Madruga, Y. Sokona, E. Farahani, S. Kadner, K. Seyboth, A. Adler, I. Baum, S. Brunner, P. Eickemeier, B. Kriemann, J. Savolainen, S. Schlömer, C. von Stechow, T. Zwickel and J.C. Minx (eds.)]. Cambridge University Press, Cambridge, United Kingdom and New York, NY, USA.

Strassburg, B. B., Rodrigues, A. S., Gusti, M., Balmford, A., Fritz, S., Obersteiner, M., Turner, R.K. \& Brooks, T. M. (2012). Impacts of incentives to reduce emissions from deforestation on global species extinctions. Nature Climate Change, 2(5), 350-355.

Streimikiene, D. \& Balezentis, T. (2013). Multi-objective ranking of climate change mitigation policies and measures in Lithuania. Renewable and Sustainable Energy Reviews 18, 144153.

Taha, RA \& Daim, T. (2013). Multi-criteria applications in renewable energy analysis: a literature review. In T. Daim, T. Oliver \& J. Kim (Eds.) Research and Technology Management in the Electricity Industry: Methods, Tools and Case Studies. (pp 17-30). London: Springer-Verlag.

Tourkolias, C., \& Mirasgedis, S. (2011). Quantification and monetization of employment benefits associated with renewable energy technologies in Greece. Renewable and Sustainable Energy Reviews, 15(6), 2876-2886.

Tyler, E. (2015). Reflecting on climate mitigation policy in a development context: how do we do what we do? Retrieved from http://www.mapsprogramme.org/wpcontent/uploads/Paper reflecting-on-climate-mitigation-policy-in-a-dev-context.pdf

Tyler, E., \& Du Toit, M. (2014). DevMit Ideas Kit. Retrieved from http://www.mapsprogramme.org/wp-content/uploads/DevMit IdeaKit web.pdf

UNEP. (2011). A Practical Framework For Planning Pro-Development Climate Policy. Retrieved from http://www.mca4climate.info

Ürge-Vorsatz, D., Herrero, S. T., Dubash, N. K., \& Lecocq, F. (2014). Measuring the CoBenefits of Climate Change Mitigation. Annual Review of Environment and Resources, 39(1), 549-582. doi:doi:10.1146/annurev-environ-031312-125456

Vilkkumaa, E, Salo, A \& Lieslö, J (2014). Multicriteria portfolio modeling for the development of shared action agendas. Group Decision and Negotiation, 23:49-70.

Von Stechow, C., McCollum, D., Riahi, K., Minx, J. C., Kriegler, E., Van Vuuren, D. P., ... \& Mirasgedis, S. (2015). Integrating global climate change mitigation goals with other sustainability objectives: a synthesis. Annual Review of Environment and Resources, 40, 363394.

Wilcock, B., Elliott, S., Hudson, N., Parkyn, S., \& Quinn, J. (2008). Climate change mitigation measures: Water quality benefits and costs. Report prepared by NIWA for MfE. Wellington, Ministry for the Environment.

Wilkinson, P., Smith, K. R., Davies, M., Adair, H., Armstrong, B. G., Barrett, M., Bruce, N., Haines, A., Hamilton, I., Oreszczyn, T., Ridley, I., Tonne, C., \& Chalabi, Z. (2009). Public health benefits of strategies to reduce greenhouse-gas emissions: household energy. The Lancet, 374(9705), 1917-1929. 
Williams, C.J., Hasanbeigi, A., Price, L.K., \& Wu, G. (2012). International Experience with Quantifying the Co-Benefits of Energy Efficiency and Greenhouse Gas Mitigation Programs and Policies. Retrieved from https://china.Ibl.gov/publications/international-experiencequantifying

Winkler, H., Boyd, A., Gunfaus, M. T., \& Raubenheimer, S. (2015). Reconsidering development by reflecting on climate change. International Environmental Agreements: Politics, Law and Economics, 15(4), 369-385.

Zhang, S., Worrell, E. \& Crijns-Graus, W. (2015). Mapping and modeling multiple benefits of energy efficiency and emission mitigation in China's cement industry at the provincial level. Applied Energy, 155, 35-58. 
Table 1 - Mitigation measures that formed part of the Co-impacts Analysis in Chile

\begin{tabular}{|l|l|}
\hline Mitigation Measure & Sector \\
\hline Energy consumption and $\mathrm{CO}_{2}$ emissions targets for new vehicles & Transport \\
\hline Public transport infrastructure & Transport \\
\hline Urban trains extensions & Transport \\
\hline Standard on cleaner carbon power generation technologies & Electricity generation \\
\hline Hydropower in Chile's south & Electricity generation \\
\hline Energy certification for existing houses & Housing and waste \\
\hline Net-billing & Housing and waste \\
\hline Composting of organic wastes & Housing and waste \\
\hline Carbon sequestration in agriculture & Land use \\
\hline Afforestation incentives & Land use \\
\hline Energy management systems & Industry and mining \\
\hline
\end{tabular}

